\title{
Constructive alignment of learning mechanics and game mechanics in Serious Game design in Higher Education
}

\author{
George Kalmpourtzis ${ }^{1}$, Margarida Romero ${ }^{2}$ \\ ${ }^{1}$ Innovation and Digital Laboratory for Education (LINE), Université Côte d'Azur, 06000 Nice, France, \\ gkalmpourtzis@playcompass.com \\ ${ }^{2}$ Innovation and Digital Laboratory for Education (LINE), Université Côte d'Azur, 06000 Nice, France, \\ margarida.romero@univ-cotedazur.fr
}

\begin{abstract}
Game design is a complex process based on balance between educational and gameplay experience in a coherent way. In the context of instructional design, Constructive Alignment aims to develop an outcome-based approach for designing learning activities during which learner engagement, through the activity, is aligned with learning objectives and outcomes. Hence, Constructive Alignment focuses on the proposal of constructively aligned learning experiences, where assessment is the result of specially selected training activities, which are proposed based on intended learning outcomes. In this study, the impact of an online MSc course on game design from a Constructive Alignment approach is assessed. Constructive Alignment in game design is approached as the coherence between Learning Objectives, Game Mechanics, Learning Mechanics and the Assessment in the educational Digital Game Based Learning. The results analysis shows that the Game Based Learning course had a positive impact on students regarding the proposal of game design documents with coherence between Game Mechanics and Learning Mechanics as well as Learning Mechanics and Learning Objectives, while little focus on integrating Assessment mechanisms was observed. Based on the results of this study an increase in focus on assessment in the process of game design is proposed.
\end{abstract}

Keywords: Game-Based Learning, Constructive Alignment, Learning Mechanics, Game Mechanics, Higher Education

\section{Introduction}

The impact of technology in education has led to various changes in the way that different stakeholders, like students, teachers, administrators and policy makers work and interact with each other. Consequently, there is a continuous academic and professional interest around educational technology and its application in learning contexts [1]-[3]. Among the various fields of educational technology, distance learning has been in the spotlight of researchers, both for its benefits in connectivity and accessibility for different learners [4] but also due to the opportunities it presents in cases where learners can't physically attend their courses. The coronavirus outbreak, causing obligatory confinement measures from several European governments has urged governments and the EU to propose distance learning tools for the delivery of learning courses [5]. Another field with increasing research interest is the one of game design and Game Based Learning (GBL), the impact of which on students' way of learning, teachers' course delivery and classroom integration has 
been approached and examined through various fields, like the ones of literacy [6], STEM [7], cognitive development [8], soft skills and creativity [9] and storytelling [10].

On top of this, researchers and educational policy makers are showing surmounting interest regarding the evolution, structure and assessment of Higher Education (HE) teaching practices in various fields. As a result, a shift towards active learning and participatory design techniques is being observed [11]. Additionally, several HE institutions are trying, or have already adopted, Outcome-Based Teaching and Evaluation processes, which aim at designing and facilitating learning activities based on sets of specified and clearly defined learning outcomes [12]. Constructive Alignment (CA) is an Outcome-Based Teaching and Evaluation framework for designing learning activities, where the learning content as well as the way that learning is going to take place is clearly stated before teaching takes place [13]. Design activities are then proposed in order to actively engage students and help them achieve those previously defined outcomes.

This study focuses on the design and delivery of a year-long online Game-Based Learning course, by the MSc SmartEdTech program of the University of the Côte d'Azur, at the end of which, students were asked to come up with their own comprehensive game design documents that would describe their games. Consisting of an important, and primarily based on, distance-learning component, its design, running and assessment has presented its instructors with several challenges. In that regard, the notion of CA has been selected both as a course design framework but, most importantly, as an assessment tool for the improvement of the course's structure and configuration. The aim of this study is to provide empirical data on the use of CA in the design of online HE programs as a course assessment tool, as well as its impact on the field of teaching game design and educational game design.

The research objectives reported in this paper are examining the impact of the university students' participation in the GBL online Masters course in regards to their (a) articulation of Learning Objectives, Learning Mechanics and Game Mechanics of the educational games they designed throughout the year-long course and (b) the interconnection and coherence between those three elements of their proposed games, using CA as an assessment tool.

\section{Theoretic background}

\subsection{Constructive alignment}

Constructive Alignment describes a teaching framework, based on two main aspects [13]. The first one is the "constructive" aspect under a constructivist approach of learning which aims to engage the students to build their knowledge, through learning and teaching activities that have been especially proposed for the context of specific learning outcomes. The other one, called the "alignment" aspect describes educators' actions aiming to help learners achieve the defined learning outcomes through the appropriate learning activities.

According to Biggs [14], CA consists of four major steps: (1) Defining the Intended Learning Outcomes, (2) choosing teaching/learning activities, which will lead to the achievement of those Intended Learning Objectives, (3) assessing students' actual learning outcomes to see how well they match the expected outcomes, (4) arriving to a final grade (Fig. 1). CA's structure is also based on the idea that students put major emphasis on final assessment [15]. The result of this approach is that, for students, assessment becomes the curriculum, since their effort will be towards passing their exams: they will pay emphasis on what they believe they will be tested on. Constructive alignment pays emphasis on the importance of 
students' Intended Learning Outcomes in order to design the learning activities which will engage the learners in effectively developing them. The aim of CA in that case is that teaching methods and assessment tasks are "aligned" to the learning activities proposed for the intended outcomes. Hence, learners are indeed indirectly directed towards the intended outcomes, through the selection of the appropriate activities and assessment tasks (Fig. 4).

The definition and expression of clearly defined Intended Learning Outcomes is of key importance in the scope of CA, since the focus needs to switch from teaching delivery to how students learn. As a result, Intended Learning Outcomes should be able to express what students should be able to do and achieve after participating in a learning activity instead of describing what teachers should do. Established taxonomies for the definition of learning objectives are already used in the context of CA, such as Bloom's taxonomy and SOLO [16], [17].

The selection of Teaching and Learning Activities is based on how engaging they can be for students and on how students can be motivated and encouraged to achieve the proposed Intended Learning Outcomes. Such types of activities can be categorized in different ways, one of which is Biggs' own categorization in self-controlled, peer-controlled and teacher-controlled activities [18]. Designing the course assessment tasks requires alignment with Intended Learning Outcomes. As a result, in order to perform assessment tasks, students will need to eventually achieve the Intended Learning Outcomes in the way they were formulated. According to Biggs \& Tang [18], "the best form of alignment is when the Teaching and Learning Activities are themselves the assessment" [p.5].

CA may also alleviate students' cognitive load, when participating in learning activities. Since nonaligned curricula and activities may distract and overwhelm students who participate in learning activities, appropriately developed activities, which are also constructively aligned, could help students focus on meaningful learning tasks, related to the specified Intended Learning Outcomes. This argument becomes even more relevant, if students' and software users' cognitive capacity is considered [19].

CA's application in teaching Digital Game Based Learning (DGBL) in HE may have a positive impact both in helping improve the quality of the provided courses but also help instructors assess their courses, based on clearly defined Intended Learning Outcomes [11]. While the field of DGBL appears to be engaging and motivating for students to participate in, the lack of connections between assessment tasks and DGBL related Training and Learning Activities may lead to a superficial or incomplete interaction between students and the games [20]. 


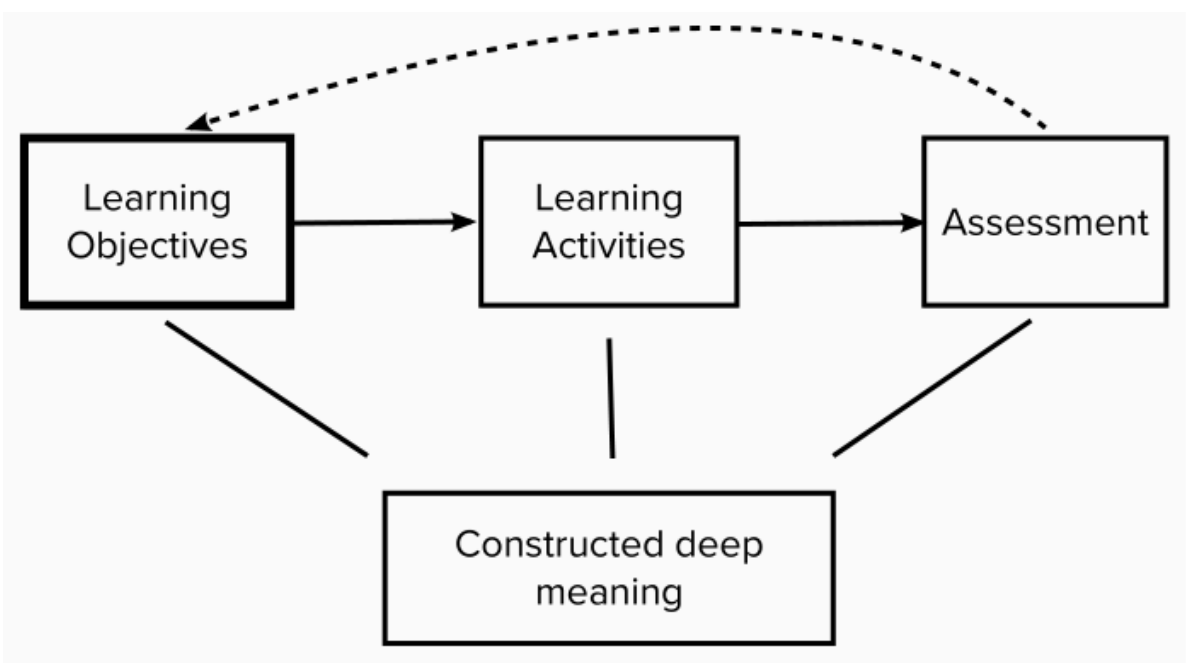

Figure 1. Constructive Alignment by Biggs (1996)

\section{$2.2 D G B L$ in $H E$}

DGBL is a field with continuous interest both from the industry and academia [21], since the introduction of games in the learning process could help shift learning deliveries from formal to learner-centered ones [22]. There are two major approaches that games have been introduced and studied upon in learning processes. The first one examines the use of games as tools for learning for specific fields [23] and the second one examines learners' participation in creating such games and the learning benefits they may incur [24].

Concerning introducing games in educational contexts for HE, there is a rich body of research, covering the fields of STEM [25], health education [26], history [27], computational thinking [2], journalism [28] and social sciences [29]. There are studies that present positive impact regarding players' knowledge acquisition [30], which is also accompanied by a positive attitude towards introducing games in classrooms [31]. It has also been observed though that the introduction of DGBL activities in HE may introduce confusion and lack of understanding on how the activities are structured, how students will be assessed and how teachers are involved in the learning process [32]. Additionally, the variety of options and tools seems to confuse educators [33]. Consequently, there are studies who have focused on the connection between learning and game mechanics [34], their intrinsic link with learning content [35] as well as organizing and structure of learning activities in the scope of DGBL [35].

The participation of learners in the creation of DGBL experiences attracts continuous research interest, taking into account the various "modding" capabilities that modern existing Commercial-Off-The-Shelf games offer or the easy access to game engines [37], [38]. Existing studies show that student participation in game making activities can have positive learning effects for the fields of 21st century skills [24], Mathematics [39], creativity [40], engineering [41], entrepreneurship [42]. Coming from the fields of Human-Computer Interaction, user participation in the creation of the software that they will later use is realized through the field of participatory design [43]. In the context of designing DGBL activities, participatory design introduces learner-centricity, where different stakeholders, including designers, educators and students are members of the design process [44].

\subsection{Constructive Alignment in the context of DGBL education}

A great challenge in educational game design teaching is the connection between teaching activities and game mechanics and educational mechanics [11]. The various connections and dependencies between the 
different components of educational games and the creation of learning content for students may be a challenge for teachers and may present a cognitive overload for students [45].

Several frameworks have been proposed for the examination and analysis of DGBL activities [34], [44][47], focusing on various aspects of DGBL, such as game design, learning experience, learning strategies, and systems design. Even if they approach the subject from different perspectives, using different approaches, there is a clear need for addressing both gaming and learning aspects in educational game design [20]. One approach to analyzing educational game design is the connection between Learning Mechanics and Game Mechanics [34]. As components of educational games, Learning Mechanics describe the underlying mechanisms and operations that implement the game designers' Learning Objectives and pedagogical principles. Game Mechanics on the other hand describe rules, interactions, structures and configurations, aiming at creating intrinsically motivating playful experiences. According to Romero et. al. [46] in the context of DGBL, Game Mechanics should be coherent in relation to the Learning Mechanics in order to avoid increasing the extraneous cognitive load, which could appear when Game Mechanics and Learning Mechanics are dissociated.

Another approach to analyzing CA in educational game design is the coherence between Game Objectives and Learning Objectives. Game Objectives describe the desired states, proposed by games, that need to be achieved when players are engaged in playing them. Learning Objectives, on the other hand, describe what students should be able to know or do after participating in learning activities. In the scope of this study, coherence is approached as the impact and relevance quality of one aspect in regard to the other. If for instance the accomplishment of Game Objectives when Learning Objectives is achieved would suggest high coherence between those two aspects. On the other hand, low effect on the achievement of Learning Objectives when Game Objectives are achieved would suggest low coherence between those two aspects. Additionally, Learning Objectives can affect Game Mechanics, in the same way that Game Mechanics may help develop or define Learning Objectives [33].

CA can be an important aspect of DGBL, since the use and adoption of educational gaming activities may be related to how they are integrated in the broader teaching design. From one hand, alignment between Learning Mechanics and Game Mechanics is required (Fig. 2) in order to reduce students' cognitive load and facilitate their learning experience through play [47]. From another perspective, alignment is also needed between Game Objectives, Learning Objectives and how these Learning Objectives are approached and achieved through Learning Mechanics. In the scope of DGBL education though, an additional component that appears through the application of CA is assessment and the selection of the proper Training and Learning Activities that will define assessment, which in turn will help students indeed arrive at the desired Intended Learning Outcomes. 


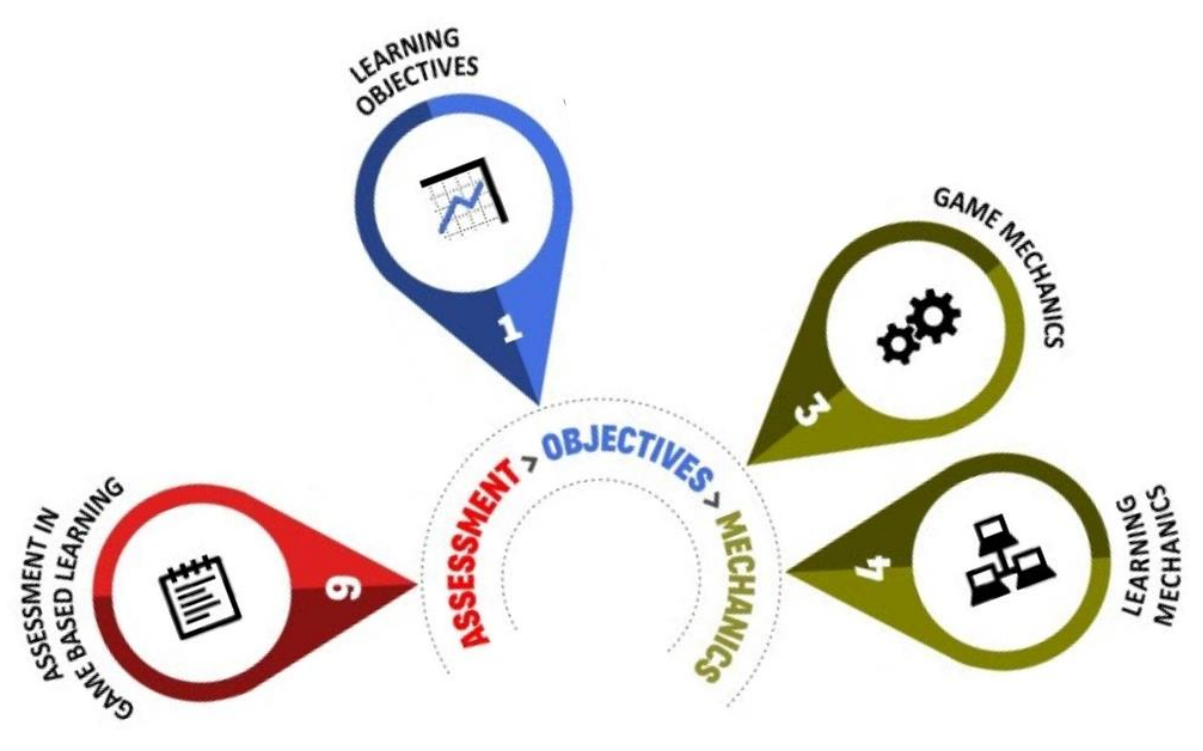

Figure 2. Constructive Alignment in DGBL

\section{Methodology}

\subsection{The MSc SmartEdTech program}

The SmartEdTech is a graduate HE distance learning program, organized by the University of the Cote d'Azur. The program consists of different course modules, all of which are delivered through the university's online Learning Management System. The program also requires that students, from all over the world, physically attend a set of program related sessions at the University's location in Nice. This set of sessions is called an "intensive week". Even if the format and configuration of different courses vary, the different modules last for a period of two semesters and include audiovisual material, remote lectures, collaborative work between students and a continuing communication between students and academic personnel, in order to clarify course-related issues as well as guide students on issues related to the presented learning modules.

\subsection{The GBL course}

Among the different learning modules of the SmartEdTech program, the GBL course focuses on helping students develop the necessary skills and understanding on how to design their own game based learning experiences. More specifically, the course's objective is to help students create educational game design competencies, including the analysis, design, learning mechanics, pedagogical integration and assessment for the experiences, under specific contexts, they want to create. As a result, students need to propose at least one game based learning experience by defining a game's Game Mechanics, Learning Mechanics, Learning Objectives, Learning Objectives, as well as the assessment around the subject matter and topic they are addressing through the experience they want to design.

The course assumes a hands-on approach, where students are required to come up with a Game Design Document (GDD) by the end of the course duration. The GBL course lasts for two semesters and starts at the beginning of the autumn semester and is concluded by the end of the spring semester of the same academic year. During the course, students have the choice to either work individually or in teams. During 
this period, students attend course lectures as well as have access to a comprehensive set of learning materials, available on the program's Learning Management System. The topic and theme of students' games was proposed by them in coordination with the course supervisor. As a result, students were free to select the topic, style and resources of their educational games. Students need to deliver their individual or teamcreated GDDs by the end of the academic year. Hence the GDDs are the course's main assessment tool for the GBL course.

A ten-step iterative design process (Fig. 3) is presented to students during the GBL course, including the following steps: (a) learning goals, (b) analyzing context and learner needs and pedagogical integration, (c) game mechanics, (d) learning mechanics, (e) game universe and game narrative, (f) prototyping, (g) development, (h) economic and distribution models, (h) assessment and learning transfer, (i) assessment of play experience and usability. This course configuration aims at helping students explore and create connections between Game Mechanics, Learning Mechanics and assessment of Learning Objectives for the educational games they propose.

The notion of CA is not explicitly presented to students during the course. However students are asked to come up with coherent serious game design proposals in relation to the different components of their games, including the games' Game Mechanics, Learning Mechanics, Game Objectives, Learning Objectives and assessment around the game's learning topic. As a result, the notion of CA is used as an assessment tool on the impact of the online GBL course on the coherence between the different elements of students' GDDs.

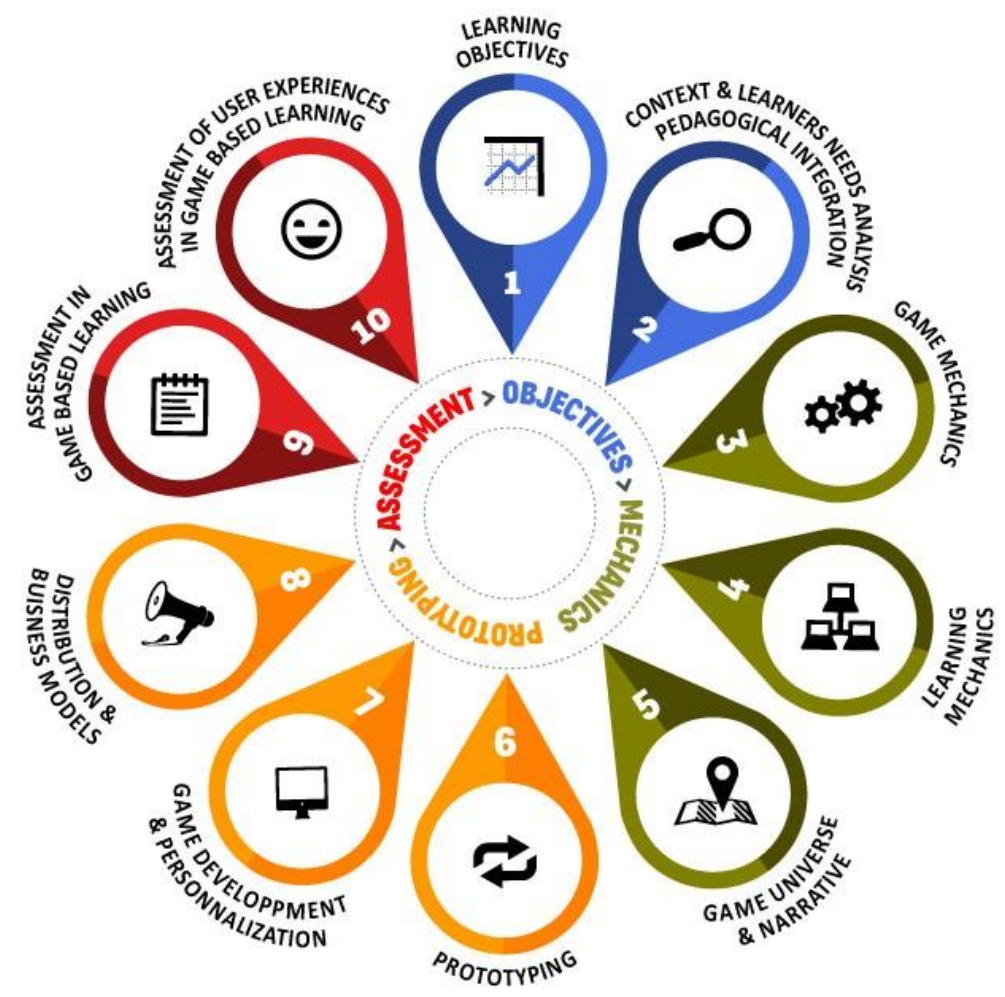

Figure 3. The design process presented during the GBL course 


\subsection{Constructive Alignment in the GBL course}

In the scope of the GBL course, CA has been used as an assessment tool for students' understanding of the process of game design. Considering that CA focuses on the creation of Training \& Learning Activities that address predefined Intended Learning Outcomes, by taking into consideration assessment from the very beginning, there are several connections between CA and GBL research. While CA encourages coherence between Intended Learning Outcomes, assessment and Training \& Learning Activities, GBL requires and entails coherence between Learning Objectives, Game Objectives, Learning Mechanics, Game Mechanics and assessment (Fig.4) [11], [33].

Since advancing through educational games requires the application of acquired knowledge during different levels, such experiences provide themselves assessment capabilities. The interconnection between Learning Mechanics, Game Mechanics and assessment could potentially implement a configuration of CA, where Training \& Learning Activities (materialized through Learning Mechanics and Game Mechanics) are themselves in some occasions the assessment, if coherence between these elements can eventually be achieved. Consequently, constructive alignment can be used as an assessment tool in the context of Game Based Learning, examining the coherence between different elements of educational games.

\subsection{The context of this study}

Within the GBL course, students were invited to develop a Game Design Document (GDD). The assessment of the GDD was based on the constructive alignment approach, operationalized as the articulation of Learning Objectives - Learning Mechanics, Learning Mechanics - Game Mechanics and Learning Mechanics -assessment and their coherence.

For the scope of this study, all assignments produced by the students of the first year of the EdTech MSc course were analyzed. The number of students who attended the GBL course in the year of this study were 13. The students, working either individually or in teams delivered 13 GDDs at the end of the academic year. Those 13 GDDs were analyzed through the scope of CA. More specifically, the degrees of coherence between the following elements were examined:

A. Learning Objectives and Learning Mechanics

B. Learning Mechanics and Game Mechanics

C. Learning Mechanics and assessment for the topics that students wanted to teach through their educational games 


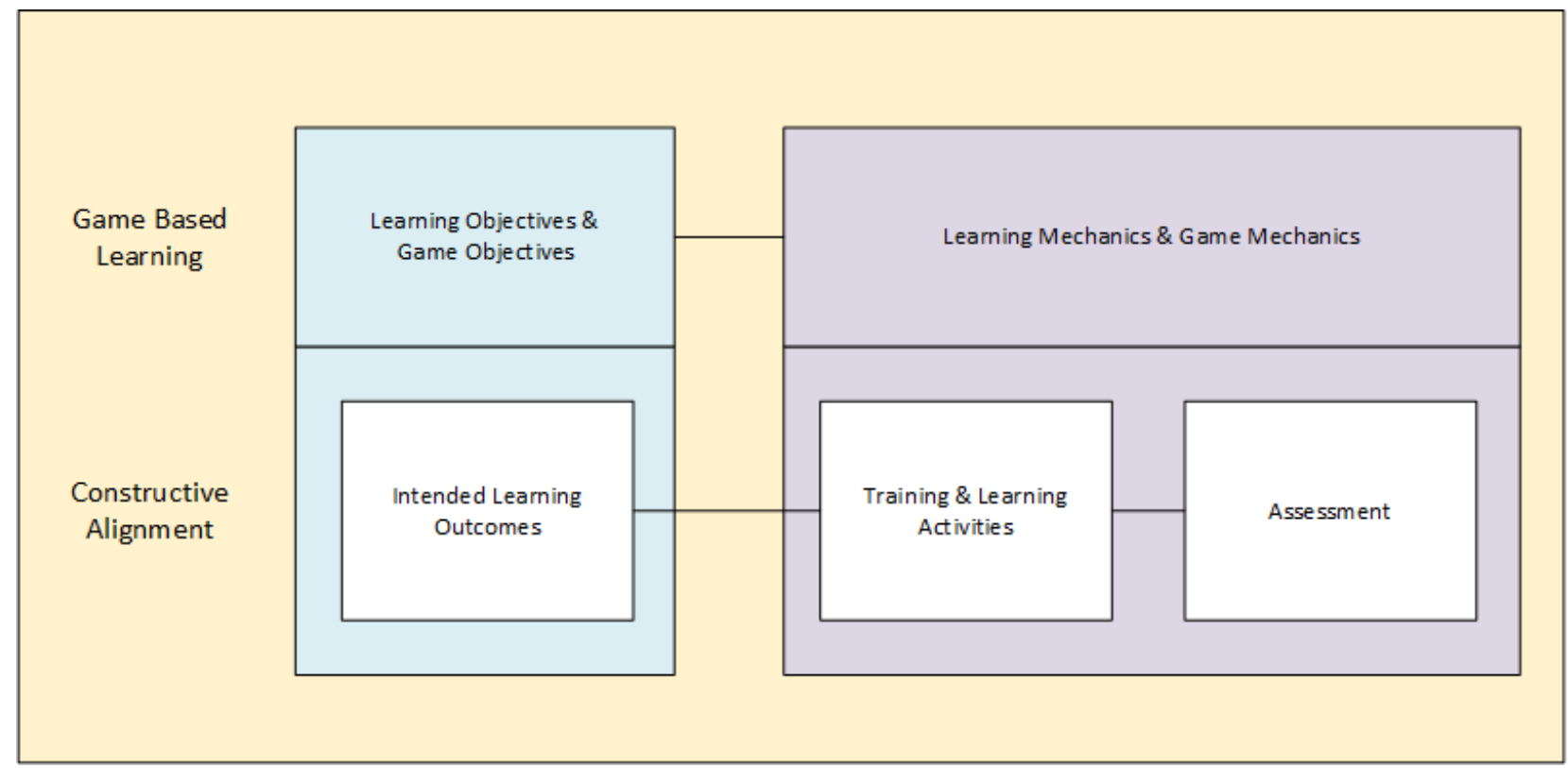

Figure 4. A connection between $C A$ and $G B L$

The submitted GDDs were analyzed by the one researcher and were later on presented and reviewed by a second one, for triangulation purposes. Each one of the three examined coherence levels was rated on a six-point scale (from 0 to 5). The scale presents five points of augmenting coherence, with 0 corresponding to no coherence and 5 corresponding to very coherent proposals.

\section{Results}

In the scope of this study, 13 GDDs have been analyzed. The analysis focused on the three degrees of coherence presented at the methodology section and consisted of the Learning Objectives - Learning Mechanics, Learning Mechanics - Game Mechanics and Learning Mechanics - assessment axis. Graph 1 presents the frequency of different ratings per axis. The analysis is presented, per axis, below. 


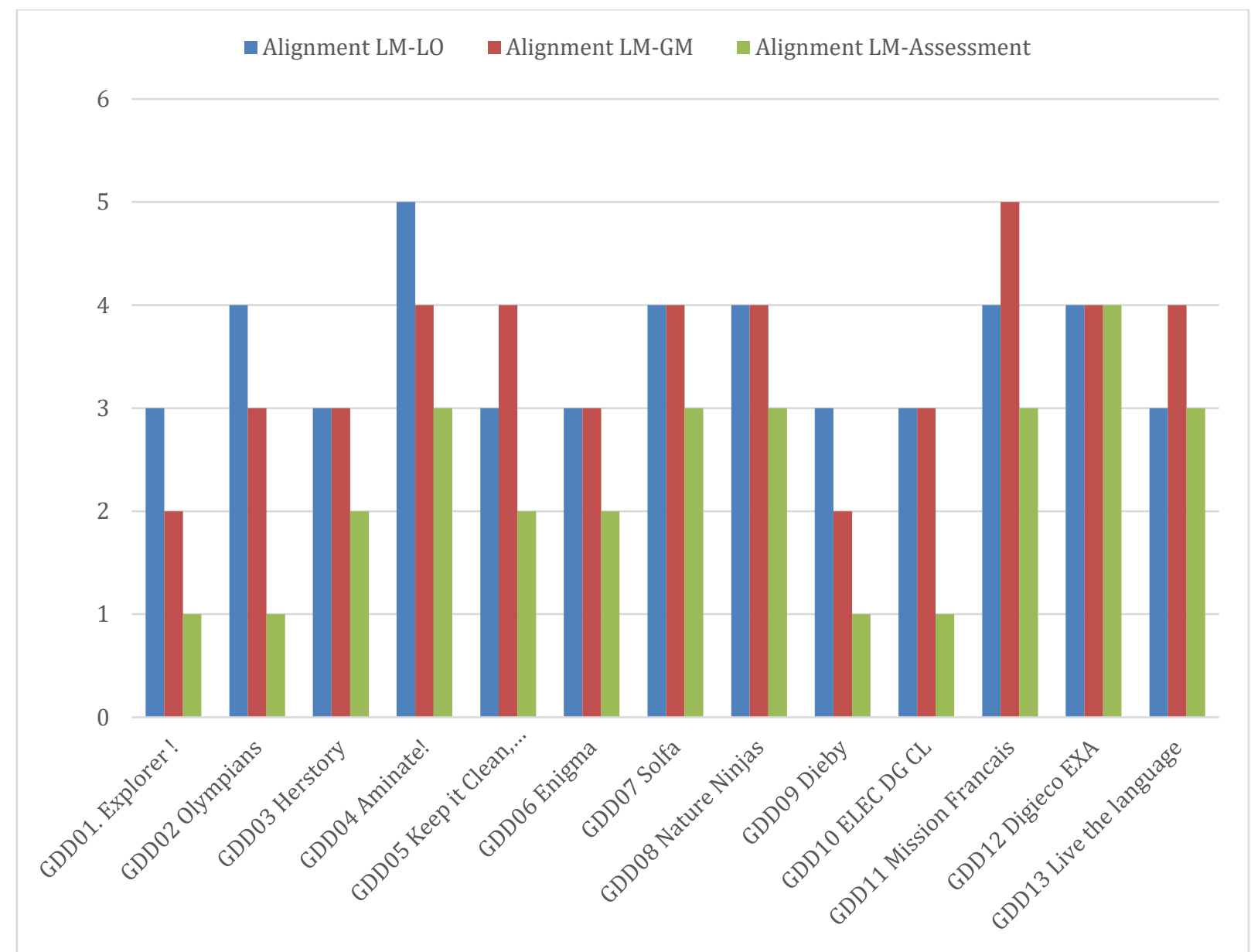

Figure 5. The frequency of scores for all examined GDDs for the Learning Mechanics (LM) Assignment, Learning Mechanics (LM) - Game Mechanics (GM) and Learning Mechanics (LM) -

Learning Objectives (LO) axis

\subsection{Learning Objectives - Learning Mechanics coherence degree}

Students of the GBL course have proposed GDDs, where the degree of coherence between Learning Mechanics and Learning Objectives is relatively high. More specifically, most analyzed GDDs showed coherence between the proposed Learning Objectives and the proposed Learning Mechanics.

An example of coherence in the axis of Learning Objectives - Learning Mechanics can be found through the GDD of the game "Olympians". The game, aiming at helping players' literacy skills with a greater focus on ancient Greek literature from Iliad and Odyssey, presents a set of learning objectives, which include the development of literacy skills and the exploration of the themes of Iliad and Odyssey, which is then accompanied by the introduction of Learning Mechanics that include simulations, guiding and on-boarding sessions as well as orchestrating decision making situations, based on the previously established Learning Objectives. On top of this, the GDD for the game "Mission Francais", a game focusing on helping players learn to speak French, presents a set of mini-game activities, aiming at addressing the Learning Objectives previously defined by the students who designed the game. Laying out the different Learning Mechanics in that form and maintaining coherence of the Learning Objectives, shows a level of constructive alignment between Learning Mechanics and Learning Objectives in this case. An example of low coherence for this 
axis can be identified through the GDD for the game "Explorer", aiming at helping highschool students to learn about the universe. The game's GDD presents a set of Learning Objectives and a brief description of Learning Mechanics. However, no apparent connection or elaboration was provided on how the game's Learning Mechanics were related to the defined Learning Objectives, neither how the latter would be achieved through the game.

\subsection{Game Mechanics - Learning Mechanics coherence degree}

Among the 13 analyzed documents, there is a considerable diversity in the span of attributed rates of coherence between the Game Mechanics - Learning Mechanics components of the proposed games. For instance, the GDD for the game "Explorer", aiming at helping highschool students to learn about the universe, presents no evident connection and interconnection between Learning Mechanics and Game Mechanics. The GDD proposes a set of Game Mechanics and a set of Learning Mechanics, not related or interacting with one another. The lack of connection between those two components introduces a misalignment both in regards to the way that the expected Learning Mechanics will in fact be implemented and materialized through the proposed Game Mechanics but also in regards to creating a cohesive learning and playful experience. Additionally, the GDD for the game "ELEC DG CL", aiming at helping students learn more about the design of electronic circuits, proposes clear Learning Objectives. However, it lacks the proposal of concise Learning Mechanics and it doesn't elaborate at all around the connection between Learning Mechanics and Game Mechanics. As a result, the actual implementation of the game and a concrete explanation of how the Game Mechanics and Learning Mechanics will help players achieve the proposed Learning Objectives remains unclear.

On the other hand, the GDD for the game "Solfa", aiming to help players learn Solfege through the "Kodaly method", presents Learning Mechanics and Game Mechanics extensively while dedicating a section to the coherence between these two game aspects by explaining how Game Mechanics and Learning Mechanics interact with each other, shaping the final educational game experience. By referencing directly the LM-GM model [34], the designers of the game, elaborate on the LM and GM interconnections and their impact on formulating and achieving Learning Objectives, through using Bloom's taxonomy [16]. Additionally, the GDD for the game "Animate!", aiming at helping students understand protein synthesis in the field of biology, presents Game Mechanics clearly while the lack of clarification regarding an aspect of the presented Learning Mechanics may cause confusion both understanding the GDD as well as correctly matching and connecting Learning Mechanics with Game Mechanics.

\subsection{Learning Mechanics - assessment coherence degree}

Throughout the analysis of all GDDs moderate to little elaboration regarding the connection and coherence between Learning Mechanics and assessment has been identified. The topic is superficially addressed by the majority of GDDs, which pay more emphasis on other aspects of the game design analysis and process. In none of the examined GDDs was there a dedicated assessment section identified, let alone a LM - assessment coherence and connection section, where students would be able to present their decision to propose the specific Learning Mechanics in regards to the potential game assessment, a topic with great importance for the notion of CA, which would later be materialized and implemented through the proposed GMs. 


\section{Discussion and future work}

The aim of this study was to evaluate students' capacity to develop coherent educational GDDs. Students were expected to express a coherent articulation of Learning Objectives, Learning Mechanics, Game Mechanics and assessment as a result of participating at the Game Based Learning course that was designed for the purpose of the SmartEdTech Masters program. The Game Based Learning course presented students with an iterative game design approach, focusing on the creation of Game Based Learning experiences. The notion of constructive alignment has been used as an evaluation tool for student deliverables, focusing on coherent and evident connections between Game Mechanics - Learning Mechanics, Learning Mechanics Assessment and Learning Mechanics - Learning Objectives.

The analysis of the delivered student GDDs showed that students were able to come up with moderately coherent to coherent designs regarding the Learning Mechanics - Game Mechanics and Learning Mechanics - Learning Objectives axis. From one side, students proposed Game Mechanics taking into account the Learning Mechanics that they wanted to apply through mini-games, separate levels or an overall Game Mechanics strategy for the games that they proposed, creating connections between Game Mechanics, Learning Mechanics and Learning Objectives. Additionally, moderately coherent to coherent designs have been observed in regards to Learning Mechanisms and More specifically, students show an understanding regarding the connection between Learning Mechanics and Learning Objectives and propose Learning Mechanics that help their players achieve the proposed Learning Objectives. The study also shows that students elaborated very little on the assessment mechanisms of their games. The topic has been mostly superficially addressed by the majority of submitted GDDs with little coherence between Learning Mechanics and the proposed assignments activities. An important implication of this result is the need to change the game design process by stressing in a more important manner the assessment activities and their coherence with the learning mechanics (Learning Mechanics-Assessment).

The present study provides empirical information regarding the use of the notion of $\mathrm{CA}$ in teaching game design in learning contexts. Even if previous studies in relevant fields have taken place [34], [35], [48], CA hasn't been previously examined in the scope of GBL education. The analysis of data suggests that the proposed MSc course has had a positive impact on students' understanding of creating GBL experiences regarding the connection and coherence between Game Mechanics - Learning Mechanics and Learning Mechanics - Learning Objectives. However, the analysis of data suggests that students had difficulty connecting player assessment with Learning Mechanics and, consequently, Game Mechanics. Potential ameliorations in the structure and points of emphasis of the course could be further explored in order to increase the coherence between Learning Mechanics and assessment in students' GDDs. As a result, either a new study for a revised curriculum for the same year or a longitudinal study, taking into account students' development and understanding of the course after the completion of the two years of the MSc program could be organized in the future.

\section{References}

[1] C. M. Foshee, S. N. Elliott, and R. K. Atkinson, "Technology-enhanced learning in college mathematics remediation,” Br. J. Educ. Technol., vol. 47, no. 5, pp. 893-905, 2016, doi: 10.1111/bjet.12285.

[2] M. Romero, A. Lepage, and B. Lille, "Computational thinking development through creative programming in higher education," Int. J. Educ. Technol. High. Educ., vol. 14, no. 1, p. 42, Dec. 2017, doi: 10.1186/s41239017-0080-z. 
[3] E. Sanchez, E. Sanchez, G. Kalmpourtzis, J. Cazes, and M. Berthoix, "Learning with Tactileo Map : From Gamification to Ludicization of Fieldwork Learning with Tactileo Map : From Gamification to Ludicization of Fieldwork," no. July, pp. 261-271, 2015, doi: 10.1553/giscience2015s261.

[4] J. Traxler, "Distance Learning—Predictions and Possibilities," Educ. Sci., vol. 8, no. 1, p. 35, Mar. 2018, doi: 10.3390/educsci8010035.

[5] European Commission, "Coronavirus: online learning resources," Official portal, Mar. 2020. Accessed: Mar. 28, 2020. [Online]. Available: https://ec.europa.eu/education/resources-and-tools/coronavirus-online-learningresources_en.

[6] C. Costa, K. Tyner, S. Henriques, and C. Sousa, "Game Creation in Youth Media and Information Literacy Education," Int. J. Game-Based Learn., vol. 8, no. 2, pp. 1-13, 2018, doi: https://doi.org/10.4018/IJGBL.2018040101

[7] G. Kalmpourtzis, "Find the Jackalop: A Game Enhancing Young Children's Spatial Thinking," in CHI '14 Extended Abstracts on Human Factors in Computing Systems, 2014, pp. 1165-1170, [Online]. Available: http://doi.acm.org/10.1145/2559206.2581506

[8] Y. Allsop, “A reflective study into children's cognition when making computer games,” Br. J. Educ. Technol., vol. 47, no. 4, pp. 665-679, 2016, doi: 10.1111/bjet.12251.

[9] M. Romero, "Digital Game Design as a Complex Learning Activity for Developing the 4Cs Skills: Communication, Collaboration, Creativity and Critical Thinking," in Games and Learning Alliance, Cham, 2016, pp. 90-99, doi: https://doi.org/10.1007/978-3-319-40216-1_10

[10] B. Dyer, "Ruminations of a road traveled towards empowerment: musing narratives of teaching, learning and self-realization," Res. Dance Educ., vol. 11, no. 1, pp. 5-18, 2010, doi: 10.1080/14647891003653393.

[11] M. Romero and G. Kalmpourtzis, "Constructive Alignment in Game Design for Learning Activities in Higher Education,” Information, vol. 11, no. 3, p. 126, Feb. 2020, doi: 10.3390/info11030126.

[12] R. M. Crespo et al., "Aligning assessment with learning outcomes in outcome-based education," in IEEE EDUCON 2010 Conference, Madrid, Apr. 2010, pp. 1239-1246, doi: 10.1109/EDUCON.2010.5492385.

[13] J. Biggs, "Constructive alignment in university teaching," p. 18.

[14] J. Biggs, "ALIGNING TEACHING AND ASSESSING TO COURSE OBJECTIVES," p. 9, 2003.

[15] P. Ramsden, "Learning to teach in higher education," Stud. High. Educ., vol. 18, no. 1, pp. 105-111, Jan. 1993, doi: 10.1080/03075079312331382498.

[16] B. S. Bloom, "Taxonomy of Educational Objectives," Educ. Psychol. Meas., vol. 16, pp. 401-405, 1956, doi: 10.1177/001316445601600310.

[17] J. Biggs, "Enhancing teaching through constructive alignment," High. Educ., vol. 32, no. 3, pp. 347-364, Oct. 1996, doi: 10.1007/BF00138871.

[18] J. Biggs and C. Tang, "APPLYING CONSTRUCTIVE ALIGNMENT TO OUTCOMES-BASED TEACHING AND LEARNING,” p. 8.

[19] J. Sweller, “Cognitive load theory,” Psychol. Learn. Motiv., vol. 55, pp. 37-76, 2011, doi: https://doi.org/10.1016/B978-0-12-387691-1.00002-8

[20] G. Kalmpourtzis, Educational Game Design Fundamentals: A journey to creating intrinsically motivating learning experiences. New York: A K Peters/CRC Press, 2018, doi: https://doi.org/10.1201/9781315208794

[21] T. Hainey, T. M. Connolly, E. A. Boyle, A. Wilson, and A. Razak, "A systematic literature review of gamesbased learning empirical evidence in primary education," Comput. Educ., vol. 102, no. February 2009, pp. 202-223, 2016, doi: 10.1016/j.compedu.2016.09.001.

[22] J. L. Tan, D. H.-L. Goh, R. P. Ang, and V. S. Huan, "Child-centered Interaction in the Design of a Game for Social Skills Intervention," Comput Entertain, vol. 9, no. 1, p. 2:1--2:17, Apr. 2011, doi: $10.1145 / 1953005.1953007$.

[23] M. M. Ariffin, A. Oxley, and S. Sulaiman, "Evaluating Game-based Learning Effectiveness in Higher Education," Procedia - Soc. Behav. Sci., vol. 123, pp. 20-27, 2014, doi: 10.1016/j.sbspro.2014.01.1393.

[24] S. Bermingham et al., "Approaches to Collaborative Game Making for Fostering 21st Century Skills," Proc. 7th Eur. Conf. Games-Based Learn., pp. 45-52, 2013.

[25] R. Khaled, "Muse-based Game Design," in Proceedings of the Designing Interactive Systems Conference, New York, NY, USA, 2012, pp. 721-730, doi: 10.1145/2317956.2318065.

[26] S. Arnab and S. Clarke, "Towards a trans-disciplinary methodology for a game-based intervention development process," Br. J. Educ. Technol., vol. 48, no. 2, pp. 279-312, 2017, doi: 10.1111/bjet.12377.

[27] F. Bellotti, R. Berta, A. De Gloria, A. D'ursi, and V. Fiore, “A serious game model for cultural heritage," $J$. Comput. Cult. Herit., vol. 5, no. 4, pp. 1-27, Oct. 2012, doi: 10.1145/2399180.2399185.

[28] A. Katsaounidou, L. Vrysis, R. Kotsakis, C. Dimoulas, and A. Veglis, "MAthE the Game: A Serious Game for 
Education and Training in News Verification,” Educ. Sci., vol. 9, no. 2, p. 155, Jun. 2019, doi: 10.3390/educsci9020155.

[29] R. Cózar-Gutiérrez and J. M. Sáez-López, "Game-based learning and gamification in initial teacher training in the social sciences: an experiment with MinecraftEdu," Int. J. Educ. Technol. High. Educ., vol. 13, no. 1, p. 2, Dec. 2016, doi: 10.1186/s41239-016-0003-4.

[30] L. F. Braghirolli, J. L. D. Ribeiro, A. D. Weise, and M. Pizzolato, "Benefits of educational games as an introductory activity in industrial engineering education," Comput. Hum. Behav., vol. 58, pp. 315-324, 2016, doi: 10.1016/j.chb.2015.12.063.

[31] M. Barr, "Student attitudes to games-based skills development: Learning from video games in higher education," Comput. Hum. Behav., vol. 80, pp. 283-294, Mar. 2018, doi: 10.1016/j.chb.2017.11.030.

[32] Y. B. Kafai and Q. Burke, "Constructionist Gaming: Understanding the Benefits of Making Games for Learning," Educ. Psychol., vol. 50, no. 4, pp. 313-334, Oct. 2015, doi: 10.1080/00461520.2015.1124022.

[33] P. Lameras, S. Arnab, I. Dunwell, C. Stewart, S. Clarke, and P. Petridis, "Essential features of serious games design in higher education: Linking learning attributes to game mechanics," Br. J. Educ. Technol., vol. 48, no. 4, pp. 972-994, 2017, doi: 10.1111/bjet.12467.

[34] S. Arnab et al., "Mapping learning and game mechanics for serious games analysis," Br. J. Educ. Technol., vol. 46, no. 2, pp. 391-411, Mar. 2015, doi: 10.1111/bjet.12113.

[35] M. P. J. Habgood and S. E. Ainsworth, "Motivating Children to Learn Effectively: Exploring the Value of Intrinsic Integration in Educational Games," J. Learn. Sci., vol. 20, no. 2, pp. 169-206, Apr. 2011, doi: 10.1080/10508406.2010.508029.

[36] E. Sanchez, S. Young, and C. Jouneau-Sion, "Classcraft: from gamification to ludicization of classroom management," Education and Information Technologies, pp. 1-17, 2016, doi: https://doi.org/10.1007/s10639016-9489-6

[37] N. Yiannoutsou and C. Kynigos, "Game Kits: Metadesign considerations on game modding for learning," in Proceedings of the The 15th International Conference on Interaction Design and Children - IDC '16, 2016, pp. 583-588, doi: 10.1145/2930674.2936000.

[38] Y. Kafai and K. Peppler, "Developing Gaming Fluencies with Scratch," in Games, Learning, and Society: Learning and Meaning in the Digital Age, C. Steinkuehler, K. Squire, and S. Barab, Eds. Cambridge: Cambridge University Press, 2012, pp. 355-380, doi: https://doi.org/10.1017/CBO9781139031127.026

[39] G. Kalmpourtzis, "Developing kindergarten students' game design skills by teaching game design through organized game design interventions," Multimed. Tools Appl., pp. 1-26, 2019, doi: https://doi.org/10.1007/s11042-019-7393-y

[40] D. Smet and S. Minoi, "Co-creativity assessment in the process of game creation," p. 10.

[41] M. Ebner and A. Holzinger, "Successful implementation of user-centered game based learning in higher education: An example from civil engineering," Comput. Educ., vol. 49, no. 3, pp. 873-890, 2007, doi: 10.1016/j.compedu.2005.11.026.

[42] F. Bellotti et al., "Designing a Course for Stimulating Entrepreneurship in Higher Education through Serious Games," Procedia Comput. Sci., vol. 15, pp. 174-186, 2012, doi: 10.1016/j.procs.2012.10.069.

[43] K. D. Könings, S. Brand-Gruwel, and J. J. G. van Merriënboer, "Participatory instructional redesign by students and teachers in secondary education: Effects on perceptions of instruction," Instr. Sci., vol. 39, no. 5, pp. 737-762, 2011, doi: 10.1007/s11251-010-9152-3.

[44] G. Kalmpourtzis, "Connecting game design with problem posing skills in early childhood," Br. J. Educ. Technol., vol. 50, no. 2, pp. 846-860, 2019, doi: 10.1111/bjet.12607.

[45] M. Dankbaar, "Serious games and blended learning; effects on performance and motivation in medical education," Perspect. Med. Educ., vol. 6, no. 1, pp. 58-60, Feb. 2017, doi: 10.1007/s40037-016-0320-2.

[46] M. Romero, L. Dumont, and S. Barma, Digital Games and Learning. Montreal, QC, Canada: JFD, 2019.

[47] J.-N. Proulx, M. Romero, and S. Arnab, "Learning Mechanics and Game Mechanics Under the Perspective of Self-Determination Theory to Foster Motivation in Digital Game Based Learning," Simul. Gaming, vol. 48, no. 1, pp. 81-97, Feb. 2017, doi: 10.1177/1046878116674399.

[48] A. Skoogh, B. Johansson, and E. J. Williams, "Constructive alignment in simulation education," in Proceedings Title: Proceedings of the 2012 Winter Simulation Conference (WSC), Berlin, Germany, Dec. 2012, pp. 1-11, doi: 10.1109/WSC.2012.6465055. 